\title{
EL MÉDICO ROMANCEADOR ALONSO DEL CASTILLO. NUEVOS DATOS A PARTIR DE LA CAPELLANÍA FUNDADA POR EL PRESBÍTERO LUIS DE LA CUEVA
}

\author{
María José Collado Ruiz*
}

Las dos personalidades sobre las que trata el contenido de este artículo se encuentran posiblemente en un sector culturalmente elevado de la sociedad granadina moderna. El caso de Alonso del Castillo es particularmente conocido, ya que a su condición de médico se le une la de haberse convertido en traductor oficial de Felipe II, y la de haber tenido entre otros el encargo de realizar una de las primeras traducciones que se hicieron de los controvertidos hallazgos que singularizan el horizonte ideológico de la Granada barroca: el manuscrito turpiano y los plomos sacromontanos. El de Luis de la Cueva tiene otras connotaciones. De este podemos presumir, que no asegurar, que fuese descendiente de cristianos nuevos. Aun así, su ordenación como sacerdote marca una característica diferenciadora a la que se le puede sumar una completa formación que se manifiesta sobradamente en su interés en la promoción educativa y sus aspiraciones eruditas con la publicación de un libro dedicado a glorificar Granada y su historia: Diálogos de las cosas notables de Granada.

\section{SOBRE LuIS DE LA CUEVA. PRESBÍTERO Y ERUDITO GRANADINO}

Difícilmente podremos encontrar las fuentes que nos aporten la información necesaria para realizar un mínimo esbozo de la personalidad de Luis de la Cueva. Por ello nos debemos remitir únicamente al estudio preliminar que hizo José Mondéjar para la edición facsímil que en 1993 editó la Universidad de Granada de los Diálogos de las cosas notables de Granada y lengua española y algunas cosas curiosas. La obra en sí presenta un escaso valor literario y viene a ser

* $\quad$ CICOP ANDALUCIA - Grupo de investigación AEDIFICATIO. 
una más de las producciones que tanto éxito tuvieron a finales del siglo XVI y hasta mediados del XVII de discurso autoencomiástico, que se dedican a recopilar noticias y datos sobre Granada, extraídos de textos anteriores, sin aportar novedad alguna. Como rasgo a destacar se podría señalar que sea una de las primeras en apoyar la teoría sobre el antiquísimo origen del español que sólo dos años antes había expuesto Gregorio López Madera ${ }^{1}$.

Uno de los aspectos que sin embargo en ella se puede rastrear es lo que el Dr. Mondéjar calificó como un mensaje subliminar, que no es otro que una encendida defensa de la causa morisca. Lo que le lleva incluso a afirmar que es muy posible que de la Cueva perteneciese a esta comunidad. Aunque su condición de eclesiástico y la irreprochable argumentación que realiza de todo aquello que se relaciona con los dogmas de la Iglesia católica le coloquen fuera de toda sospecha. Inclusive cuando aprovecha este texto para sumar sus esfuerzos en pos de las reliquias halladas en el monte Valparaíso, adjudicando la gloria de su descubrimiento a unos moriscos ${ }^{2}$.

Hay una circunstancia que llama poderosamente la atención de José Mondéjar y es el hecho de que los Diálogos se publicaran en la ciudad de Sevilla y no en la de Granada, dado el particular y extendido elogio que de la misma realiza en múltiples ocasiones con el intento de demostrar con curiosos ejemplos la antigüedad y valía de todo lo que de ella se deriva. Hay un sentimiento no sólo de adhesión a las principales causas que movilizaban a las fuerzas vivas de esta ciudad en los albores del siglo XVII, sino inclusive un atisbo de cercanía más íntima y sentimental que seguramente estaban motivadas por el amor que el licenciado de la Cueva le tenía a Granada como su patria natal o por una larga y fructífera estancia en la misma. El caso es que difícilmente se puede entender que se pusieran dificultades a la publicación de esta obra en Granada, por lo que serían otros los motivos que harían que viera la luz en la capital hispalense. Apuntándose en el prólogo antes referido el que en esos años estuviera en esta ciudad al servicio del cardenal Niño de Guevara, a quien se la dedica ${ }^{3}$.

Independientemente de los datos más o menos precisos que los diálogos nos pudieran aportar sobre su autor, otros le han hecho merecedor de alguna cita en crónicas como la de Bermúdez de Pedraza que menciona al licenciado Luis de la Cueva como "diligente investigador destas antigüedades (las de Granada) y gran matemático" ${ }^{\prime 4}$. Sobre este pormenor difícilmente podremos aportar novedad alguna en el transcurso de este artículo, sin embargo, y vol-

1. G. LóPez MADERA, Discursos de la certidumbre de las reliquias descubiertas en Granada desde el año de 1588 hasta el de 1598, impreso con licencia en Granada por Sebastián de Mena, 1601.

2. L. de la Cueva, Diálogos de las cosas notables de Granada y lengua española y algunas cosas curiosas, estudio preliminar José Mondéjar, ed. facsímil, Granada, 1993 (1603), p. XVIII.

3. La obra de Luis de la Cueva se editó en Sevilla por el impresor Fernando de Lara en 1603.

4. F. Bermúdez de PedrazA, Historia eclesiástica de Granada, ed. facsímil, prólogo I. Henares Cuéllar, Granada, 1989 (1639), fol. 8 v. 
viendo a la elocuente disertación del Dr. Mondéjar, lo que se trasluce en el transcurso de su obra es que el licenciado era un hombre de gran cultura, como reflejan la cantidad y variedad de notas eruditas que incluye, algunas sin referencia expresa del autor. Todo ello ahondando en la misma dirección, el denodado intento por exaltar el mérito de todo lo granadino.

Es en esta tesitura donde creemos puede resultar esclarecedor el testimonio que en primera persona nos deja el licenciado de la Cueva en su propio testamento y del cual hemos estudiado un traslado autentificado que se incluye en un expediente abierto en el Juzgado de testamentos, obras pías y patronatos que se conserva en el Archivo Histórico Diocesano del Arzobispado de Granada. Una de las secciones más interesantes de este archivo es sin duda la que constituyen los ciento trece legajos que componen la sección denominada "E", que se corresponde con los expedientes de patronatos que llegaban a esta sección. Más concretamente, la documentación que ahora utilizamos para la realización de este artículo es parte de la que se generó a consecuencia del proceso incoado por las sucesivas denuncias entre los patronos y capellanes de una de las obras piadosas fundadas por Luis de la Cueva en su testamento ${ }^{5}$.

En el expediente que hemos tenido la oportunidad de consultar se incluyen entre otros, los traslados autentificados del testamento que el licenciado de la Cueva otorgó ante el escribano público de la ciudad de Granada Gregorio de Arriola el veinticinco de mayo de 1616 y el de un codicilo fechado el diecinueve de febrero de 1618. De su lectura creemos que podemos extraer algunos datos más acerca de la personalidad de este erudito local, cuya biografía se haya reducida a la información previamente reseñada.

En el texto que pretende sea su última voluntad Luis de la Cueva se presenta simplemente como presbítero, circunstancia esta sobradamente conocida, aunque clarificadora, ya que no añade que tenga un cargo específico o que hubiera conseguido algún puesto por encima de la condición sacerdotal, algo que habría sido habitual consignar en un documento de esta época, en el que se suele ser muy prolijo a la hora de enumerar cargos o dignidades alcanzadas. Ahora bien, lo que inmediatamente se convierte en una declaración de intenciones es su profesión de fe. Sin tener como base un estudio estadístico de esta manda testamentaria concreta, y aportando la experiencia adquirida en el desarrollo de nuestra tesis doctoral sobre La cultura de la muerte en la Granada del Antiguo Régimen, apreciamos que la fórmula utilizada resulta bastante llamativa ${ }^{6}$. Así al menos

5. A.H.D.Gr., Sección Patronatos, Leg. 14. Expediente sobre las capellanías fundadas por el licenciado Luis de la Cueva. A partir de este momento los datos y citas directas que aparezcan se corresponden con la documentación de que consta este expediente, por lo que no se reseñará específicamente y de modo individual en citas a pie de página, para hacer más ágil la lectura de este artículo.

6. M.J. Collado RuIz, La cultura de la muerte en la Granada del Antiguo Régimen. La memoria última. Tesis doctoral dirigida por Dr. Rafael López Guzmán, defendida en el Departamento de Historia del Arte de la Universidad de Granada, 7-noviembre-2007. 
nos lo pareció durante el transcurso de la investigación previa que tuvimos que realizar para la documentación de la misma, ya que en ella muestra una adhesión total a los postulados defendidos por la Iglesia católica, circunstancia esta habitual en los testamentos, pero a la que él añade un tono muy personal y un cierto toque ilustrado al incluir los argumentos del profeta Isaías y las instrucciones que en la hora de su muerte dio san Francisco a sus hermanos, para refrendar la fuerza de su fe. Alude a la incapacidad del raciocinio humano para alcanzar a comprender la que denomina como "inmensa sabiduría de Dios". Explicando que su convicción es tan firme que le resultan innecesarias las muestras sobradas que Dios ha dado al hombre en forma de milagros y apostilla con una fórmula que nos resulta especialmente curiosa "aunque no ubiera echo Dios tantos milagros desde que nació Xpto hasta oy es gracia misericordia de Dios que en todo tiempo aya avido milagros en su iglesia". Siendo rigurosos en la interpretación de este tipo de afirmaciones, no podemos encontrar en ellas ninguna mención concreta a un hecho milagroso, pero nos parece que de una lectura entre líneas se podría deducir el que Luis de la Cueva opinara que este tipo de acciones providenciales o milagrosas siguen teniendo vigencia en su época. Y con ello apuntara a acontecimientos recientes acaecidos en su entorno.

Realizar una defensa tan firme de su catolicidad en el testamento quedaría como un hecho restringido a un ámbito muy privado y cercano, ya que no serían muchos los que asistieran a la apertura y lectura de dicho documento. Sin embargo, su posición quedaría manifiestamente expuesta en el momento en que especificara el modo en que dice quiere ser enterrado en la iglesia de Nuestra Señora de las Angustias, bajo una lápida en la que junto a su nombre se grabe la siguiente inscripción "no puede herrar la santa iglesia romana". Posiblemente sea un riesgo interpretar con tanta distancia las expresiones que emplea en su testamento, pero aun así parece incidir particularmente en la condición que expresamente ha señalado como su epitafio con el hecho de disponer que su sepultura sea "mercada", es decir, que se la compre para su único uso. Circunstancia esta que le haría ser su ocupante exclusivo, al no declarar herederos y tener muertos y enterrados en otros conventos de la ciudad a sus ascendientes, y que por tanto perpetuarían la inscripción que tan explícitamente quiere que se convierta en única voz de su sepultura: su identificación nominalmente y como sacerdote, la fecha de su muerte y la infalibilidad de la iglesia de Roma. Es seguramente en este tipo de aseveraciones en las que encontramos una total coincidencia en lo que ya había expresado el Dr. Mondéjar sobre que el licenciado de la Cueva se apartaba de cualquier sospecha que pudiera recaer sobre la pureza de su fe y su ortodoxia.

Pero hay algunos aspectos más sobre la intimidad y circunstancias vitales de una persona que dispone el destino último de sus bienes cuando siente la muerte próxima que todavía están por descubrir en el transcurso de la lectura de su testamento. Aunque no expone muchos datos sobre su familia, señala una particular predilección por la que entendemos debe ser su hermana, María de la Cueva. De ésta relaciona que murió virgen a los setenta y cinco años de 
edad y que desde los dieciocho que "dejo las galas" (es decir que se retiró a vivir recogidamente en unas condiciones que debían asimilarse a las que tenían las religiosas de su época), había vivido castamente. De ella dice que era muy hermosa, lo que sin duda añade con intención de aumentar el valor de su renuncia y que a pesar de su carácter colérico (apreciación que no debemos entender con una valoración negativa, sino que se señalaba en su época como un rasgo propio del carácter femenino) nunca la vio maldecir. Incluso se atreve a dudar que en ese tiempo alguna vez pecara mortalmente. Llegando en consonancia a su humildad a liberar un esclavo con uno de los gestos que se tenían como tradicionales para la manumisión: besarle la mano antes de morir.

Precisamente por su alma dispondrá algunas mandas muy interesantes, como la de que le dijeran una misa cantada el día de la Inmaculada Concepción, en la capilla en la que fue enterrada, que es la de la Humildad del convento de mínimos de la Victoria. Además quiere que se diga "en memoria de que no tuvo pecado original como lo dicen los libros del Montesanto y las revelaciones de Santa Brigida".

Traemos a colación esta manda testamentaria porque si bien podría enmarcarse dentro de la normalidad de su tiempo prever misas por la salvación del alma de sus parientes más cercanos, entendemos que es prácticamente un compendio de la religiosidad granadina más exacerbada en el especial momento en que se redacta este documento. Por un lado se adscribe a la defensa del dogma de la Inmaculada Concepción de María en unos años cruciales en la controversia y definición del mismo. Pero lo que redunda en su originalidad e interés es la alusión que hace respecto a los Libros del Sacromonte y las revelaciones de Santa Brígida.

Citar expresamente la defensa del todavía no proclamado dogma inmaculadista, en el modo en que aparece en los textos plúmbeos hallados sólo unos años antes en las cuevas del Monte Valparaíso de la ciudad de Granada, lo posicionan en el bando de aquellos que defendían en abierta actitud la veracidad de un descubrimiento que por entonces se movía entre profundas controversias.

Es en el marco de la polémica suscitada por la falsedad o intento desesperado de sincretismo religioso y cultural que habitualmente ha estado en la base de la polémica de los hallazgos granadinos, donde puede resultar esclarecedor señalar algún dato más sobre la persona y obra de Luis de la Cueva. Como buen católico se encargará de que la totalidad de sus bienes se empleen en diversas obras piadosas encaminadas a trabajar en pos de la salvación de su alma y de las de sus allegados, como ya hemos visto en el caso de su hermana. $\mathrm{Su}$ fundación principal será la de dos capellanías de misas que se deben decir en la iglesia de las Angustias. Estas deberán correr a cargo de dos capellanes, tendrán una carga de ciento ochenta y siete misas al año y se sustentarán con sesenta y ocho ducados que saldrán de las rentas que proporcionen sus propiedades tras haber pagado los gastos generados por su entierro y funeral. El patronato de las mismas recaerá en la persona que designe el Hospital de Juan 
de Dios de la ciudad de Granada y deberá tener una serie de precauciones. Como que los sacerdotes que las sirvan sean descendientes de sus primos y primas y residentes en la ciudad, durante al menos los últimos diez años. No quiere que ambas recaigan en una misma persona, ni que el valor de la misa exceda de los cuatro reales. Los bienes inmuebles sobre los que se cargarán estas fundaciones no deben venderse y los patrones y capellanes serán los encargados de que estén saneados y reparados.

Hay una condición muy especial que impone en esta fundación y que se expresa en el momento en que decide que el número de misas por su alma se acreciente en caso de tener las rentas suficientes, excepto si alguno de los capellanes "lee una lección de esfera". Es esa faceta erudita de Luis de la Cueva la que aparece en esta situación, ya que se muestra como un ferviente promotor del estudio de la astrología, al promover de algún modo que parte de sus rentas se empleen en el incentivo que debía suponer para un eclesiástico del momento el beneficio de una capellanía que le permitiese su asistencia regular a la Universidad. La afición por la astrología, y entendemos que por extensión por las matemáticas, tal y como ya había señalado Bermúdez de Pedraza, no sólo se puede observar en esta acción sino también en algunos de los objetos personales cuyo destino dispone en su testamento. Así ordena un legado muy particular para un convento descalzo de la ciudad que no especifica y entre otros quiere que se le entreguen sus libros y "artes", una esfera y un reloj de noche de cobre.

Habría resultado muy interesante conocer la almoneda de los bienes del licenciado de la Cueva, acción esta que dispuso en un codicilo posterior, ya que es muy posible que gracias a la documentación que de ella se hubiera generado pudiéramos conocer el contenido exacto de esas artes astrológicas y la temática de los libros que componían su biblioteca.

\section{LUIS DE LA CUEVA Y EL MÉDICO ROMANCEADOR Alonso del Castillo}

Uno de los datos que consideramos más interesantes para establecer el ámbito de relaciones del licenciado de la Cueva no lo aporta directamente su testamento, sino uno de los documentos que se anexan en el expediente conservado en el Archivo Histórico del arzobispado granadino, y es el contrato de compraventa de una casa situada en la "colación" de San Miguel. Este contrato está fechado el veintisiete de enero de 1614, es decir dos años antes de que se redactara el testamento. Lo que ha llamado poderosamente nuestra atención es descubrir la identidad del vendedor de la misma: Alonso Jiménez tejedor de mantos, nieto de Alonso del Castillo, "medico romanceador de letras arábigas".

De la lectura de este contrato podemos extraer básicamente las características generales de la vivienda. Ésta se sitúa como dijimos en el entorno de la parroquia de San Miguel, el acceso se hace por la calle Horno de la Escalerue- 
la y linda con las propiedades del doctor Trigoso y de la viuda de Alonso Hernández y Guijarro. La casa se vende libre de censos y se acuerda un precio por ella de cien ducados, de los cuales mil reales en moneda de vellón se entregan en el momento de formalizar la escritura y se comprometen a completar el pago (cien reales) en el plazo de un año.

Podríamos deducir que esta compra fue una inversión en bienes inmuebles por parte del licenciado de la Cueva, ya que éste debía de tener una economía relativamente saneada, según menciona la cantidad de dinero que estima debe tener en su vivienda en el momento de otorgar su última voluntad, que asciende, siempre según sus cálculos a los tres mil reales. Además el hecho de ser vecino de la parroquia de San Pedro y San Pablo implica que su vivienda no era la que había comprado a los descendientes del famoso traductor. Pero además puede apuntar en la dirección del estrecho círculo de relaciones que se establecían entre la población de origen morisco que habitaba en Granada. Así ya lo exponía Darío Cabanelas al hablar de las amistades frecuentadas por Alonso del Castillo ${ }^{7}$.

Es ésta una ocasión que se nos presenta para intentar aportar algunos datos a la tan sabida, y aún no esclarecida, biografía del singular médico granadino Alonso del Castillo. La información más relevante al respecto es la que hasta el momento nos ha legado el libro que Cabanelas le dedicó en 1965. En fechas más recientes parece que están saliendo a la luz algunos documentos más que pudieran alumbrar, si no las principales tareas oficiales llevadas a cabo por el famoso morisco, sí pequeñas pinceladas que progresivamente van completando su semblante profesional y personal. Es en esta última faceta donde esperamos que el presente artículo pueda aportar todavía unas documentadas referencias sobre este personaje.

Incluso el padre Cabanelas no se atrevió más que a titular como "esquema de una biografía" el primer capítulo que dedica a la que califica como "compleja personalidad" de Alonso del Castillo. Él había contado con la excepcional información que le ofrecían fuentes autógrafas como el manuscrito 7453 de la Biblioteca Nacional en que se recogen de su mismo puño y letra importante correspondencia, variedad de temas léxicos y la traducción de las inscripciones de la Alhambra. También contribuyó con un riguroso estudio de documentos procedentes del Archivo de la Abadía del Sacromonte, de la Real Academia de la Historia, de la Biblioteca del Escorial y de los registros de la parroquia de San Miguel. Aun con el riguroso estudio de todo este material, serán muchos los aspectos de la vida y obra de Alonso del Castillo que reconoce ignorar y en los que pretendemos ahondar a continuación.

Entre la documentación que se incluye en el expediente de las capellanías fundadas por Luis de la Cueva hemos señalado que se encontraba el contrato

7. D. Cabanelas Rodríguez O.F.M., El morisco granadino Alonso del Castillo, Granada, 1965, pp. 21-22. 
de compraventa de una casa que había pertenecido a Alonso del Castillo. Ubicada en el núcleo del barrio del Albaicín, habitado por una población mayoritariamente morisca durante todo el siglo XVI, tenía una estructura tradicional de casa patio. Pero, aparte del precio en que se estimó, de las propiedades colindantes y de la calle por la que tenía su acceso, poco más se puede extraer del sucinto contrato. Sin embargo, el propietario en el momento de realizar la transacción, Alonso Jiménez, nieto de Alonso del Castillo, aporta un documento con el que pretende explicar el modo en que esta vivienda se había incorporado al patrimonio familiar años atrás. Concretamente una Real Provisión firmada por el presidente de la Real Chancillería, Pedro de Deza, en que se hace eco de la concesión por parte de Felipe II de una serie de prebendas, entre las que se incluye la citada casa.

Es muy posible que Alonso Jiménez, con esta acción, simplemente estuviera acreditando el ser titular de los derechos que le permitían vender la casa. Ahora bien, a la vez nos estaba abriendo las puertas al conocimiento de uno de los privilegios que el rey otorgó a Alonso del Castillo, en virtud de los múltiples servicios que en calidad de traductor estaba prestando a la Corona en momentos tan decisivos como los que acontecían en los albores del siglo XVII, con la sublevación de los moriscos y su posterior expulsión.

Esta carta real está fechada en Granada el veinticuatro de septiembre de 1575, es decir, tras regresar a la ciudad ${ }^{8}$ después de su primera estancia en El Escorial donde había estado realizando un catálogo de manuscritos árabes por encargo de Felipe $\mathrm{II}^{9}$, y obviamente antes de que se le nombrase traductor oficial en $1582^{10}$. Por lo que aún sin haber recibido este reconocimiento, a sabiendas de la valía de su trabajo como "romanceador", se le hacen una serie de concesiones que probablemente él reclamara y que quedaran recogidas por escrito para mostrar su validez. Así, en el reverso de esta carta se ha escrito a modo de título el contenido esencial de la misma: "Para que las justicias del Reyno dexen estar y bibir en el al licenciado Alonso del Castillo medico de los naturales de dicho Reyno con su casa muger e hijos y hazienda y con el a Garcia del Castillo su hermano".

Sólo con la lectura de estas líneas podemos deducir que la carta en cuestión debía funcionar como una especie de salvoconducto que Alonso del Castillo tenía especial interés en poseer para garantizarse la tranquilidad propia y de toda su familia. Pero no son éstos los únicos aspectos que se contemplan en el mismo. Remitiéndonos al cuerpo del documento, podemos extraer una relación de acontecimientos que nos ayuden a completar el trabajo tan exhaustivamente realizado por Darío Cabanelas. Por ejemplo, tras la fórmula de en-

\footnotetext{
8. Ibídem, p. 128. Recoge que el 8 de enero de 1575 está en Granada y escribe una carta a Pedro de Deza sobre la sublevación y reducción de los moriscos del Reino de Granada.

9. Ibídem, p. 124.

10. Ibidem, p. 132.
} 
cabezamiento de la carta se menciona expresamente el hecho de que la misma fue demandada por el licenciado Alonso del Castillo, a quien de partida se le presenta como vecino de Granada y "de los naturales de aquel reino", lo que alude directamente a su origen morisco. Inmediatamente se explica la motivación de esta demanda: permitir a del Castillo seguir residiendo en Granada tras la publicación de los primeros edictos sobre la reducción y expulsión de la población neoconversa: "le hiciesemos de dar licencia para que sin embargo de los bandos publicados pudiese vivir en el dicho reino y gozar de su hacienda". Y este favor se le otorga precisamente "atento a lo que nos avia servido en la rebelion y lebantamiento de los moriscos".

Ahora bien, se añade un detalle que resultará de particular interés; que junto a Alonso pueda quedarse su hermano, a condición de que le enseñe a traducir el árabe, o literalmente "mostrandole el oficio de romançador de la lengua araviga". Con esto se señala de algún modo el aprecio que se tenía a Alonso del Castillo como traductor y el interés mostrado por parte del monarca en que su sabiduría no se perdiera con él (que por entonces debía ser un hombre de edad avanzada) y se transmitiera a su hermano, con el objeto de dar continuidad a su tarea al servicio de los intereses de la Corona española.

Esta carta incluye la referencia a lo que era el proceso habitual de información sobre la "persona y servicios" del licenciado del Castillo que se encargará de emitir, con fecha de dos de marzo, el presidente de la Real Audiencia, Pedro de Deza. Lo favorable del mismo le hace merecedor de que "no sea sacado", es decir, expulsado del Reino de Granada. Además se hace relación de la concesión de la casa objeto de la compraventa anteriormente referida, de la que se especifica "le abemos hecho merced por sus días de una casa en el albayzin desa ciudad en que biba" y una licencia que debía tenerse por excepcional, la de tener armas.

Estas son sin duda unas prebendas muy especiales que sólo tendrían cabida en casos muy señalados, como debía ser el licenciado Alonso del Castillo, quien a los ojos de las autoridades civiles y religiosas habría alcanzado una alta estima y en quien no recaería sombra alguna de sospecha en los recientes episodios de la guerra pertrechada contra los moriscos del antiguo Reino de Granada, durante la cual desempeñó su oficio de traductor, tanto en la capital granadina como en el campo, al servicio del duque de Sesa ${ }^{11}$.

Continuando en nuestro intento por esclarecer los todavía oscuros aspectos que salpican la biografía de Alonso del Castillo, podemos concluir que la casa en la que este vivió en el Albaicín granadino habría sido una propiedad concedida por designio del monarca en pago a sus buenos servicios. Pero todavía hay alguna información más dispersa entre el expediente de las fundaciones piadosas del sacerdote Luis de la Cueva, ya que se incluye el testimonio

11. Ibídem, p. 75. 
de un escribano, Juan Calvo Navarro, fechado en enero de 1614, en que declara cómo Alonso del Castillo, a quien presenta como "interprete de su majestad", había otorgado testamento ante él señalando como su universal heredero a su nieto, Alonso Jiménez. Este que hemos visto era el que vendía la casa, y se detalla que era hijo de Miguel Jiménez y de Escolástica del Castillo, hija legítima de Alonso, quien ya había muerto en el año en que su padre hace testamento.

Otra vez más nos encontramos ante un documento que refrenda el derecho de Miguel Jiménez a disponer de la propiedad que se pone en venta, por lo que la declaración del escribano explicitando que él había sido designado como heredero de su abuelo es fundamental. Sin embargo, habida cuenta que el dato exacto de la fecha de defunción de Alonso del Castillo era algo que se desconocía y que se había fijado entre 1607 y $1610^{12}$, pensamos que puede ser interesante al menos conocer la que otorga su testamento, el veinticinco de mayo de 1607. Entendiendo que cabe la posibilidad de que, como era bastante habitual en esta época, no transcurriera mucho tiempo entre el momento de otorgar las últimas voluntades y el óbito. También es posible ampliar el conocimiento sobre su familia más cercana, ya que no eran muchas las alusiones que de ella se hacen en las fuentes hasta ahora estudiadas. Así, la hija casada de la que habla el padre Cabanelas ${ }^{13}$ podía ser Escolástica, que ya estaba muerta en 1607 y que había dejado un hijo que sería el único heredero de su abuelo. Cabe la posibilidad de que el marido de Escolástica, Miguel Jiménez, fuese el yerno, cuyo nombre también desconoce el investigador franciscano. Aunque como él prudentemente nos apunta, Alonso pudo haber dejado una mayor descendencia y por tanto no tener total certeza sobre esta identificación que ahora apuntamos. Las citas sobre un hermano de Alonso del Castillo, llamado García del Castillo, también aparecen en el estudio que Darío Cabanelas hizo sobre el famoso médico morisco $^{14}$. De este se detalla que vivía en Jerez de la Frontera y entendemos que debió pasar a residir en el entorno más próximo de Alonso para que pudiera transmitirle el oficio de romanceador, tal cual se dispone en la provisión real.

Uno de los aspectos que hemos encontrado más interesante a la hora de abordar este trabajo ha sido intentar descubrir el modo en que se tejía un cerrado círculo de relaciones de amistad entre la población morisca más destacada de la antigua capital nazarí. Si Alonso del Castillo se movía y participaba activamente de la vida de aquellos con los que compartía un indisoluble nexo racial y lingüístico (y hemos dejado de mencionar expresamente el religioso) es algo que ya apuntó Darío Cabanelas en el texto que le dedicó en 1965 y que hemos

12. El padre Cabanelas estableció este margen, ya que tenía constancia documental de que en 1607 Alonso del Castillo estaba trabajando en la interpretación de los libros plúmbeos. El primer libro de enterramientos de la parroquia de San Miguel en la que fue inhumado comienza en 1610 y no hay registro alguno del suyo.

13. Ibídem, p. 5 .

14. Ibídem, p. 7. 
citado recurrentemente. Ahora bien, tras la revuelta y expulsión del grueso de esta población su círculo se estrechaba considerablemente, y además podía inclusive generar algún tipo de duda si no actuaba con precaución. Pauta esta que debió de guiar su conducta, ya que parece que la sombra de la sospecha no recayó jamás sobre su persona, ni en lo que concierne a las circunstancias que llevaron al levantamiento de los conocidos como cristianos nuevos, ni en lo que después se convirtió en principal tema de polémica: su posible participación en la autoría del manuscrito turpiano y en los libros plúmbeos.

$\mathrm{Su}$ honestidad y la ortodoxia de sus creencias fueron defendidas por el mismo Pedro de Castro años después de la muerte del traductor, cuando el catolicismo de éste y de su colega Miguel de Luna fueron puestos en entredicho. En una carta que escribió en 1618 habla de Alonso del Castillo como hombre de bien, servidor del rey en las rebeliones y menciona expresamente cómo a él le permitieron quedarse mientras los demás fueron sacados del reino. Para avalar su catolicidad relata que murió tras haber recibido los preceptivos sacramentos y cantando el credo, habiendo hecho su testamento y enterrándose en la parroquia de San Miguel con todos los sacrificios y misas de ánimas que son preceptivas ${ }^{15}$.

A pesar de este testimonio, la participación de Alonso del Castillo en la falsificación de los controvertidos hallazgos se ha dado por segura desde que se comenzó la investigación de los mismos ${ }^{16}$. No sabemos con exactitud cómo estas circunstancias pudieron concurrir en la vida cotidiana de sus descendientes en Granada y si éstas pudieron influir en el hecho de que su nieto vendiera la que había sido su casa, seguramente parte importante del patrimonio familiar, no mucho tiempo después de la fecha en que estimamos pudo morir su abuelo ${ }^{17}$.

Alonso no sólo había recibido el nombre de su abuelo sino que también había ejercido la medicina y entre sus cualidades estaba el conocer varias lenguas, incluida la árabe, que al parecer había aprendido de pequeño en su casa de Granada. También a través de su abuelo se le habría encomendado la tarea de enseñar el árabe a algunos sacerdotes a quienes el arzobispo granadino había encargado traducir los plomos del Sacromonte. Por lo que vemos, la ca-

15. Ibidem, pp. 14-15.

16. Ibídem, pp. 230-231. Prácticamente cuando concluye su estudio sobre el morisco Alonso del Castillo acaba dando por hecho su participación en el intento de falsificación de estos hallazgos, poniendo simplemente en duda el grado de participación en el mismo. M. GARCíA-ARENAL («El entorno de los plomos: Historiografía y linaje», Al-Qantara, XXIV, 2, 2003, pp. 295-326) apunta hacia los autores de la falsificación exponiendo cómo ya estos fueron señalados en fechas muy recientes a los hallazgos por parte de Luis del Mármol y de Marcos Dobelio, p. 297.

17. Las referencias que hasta fechas recientes teníamos sobre las dificultades que estaba pasando otro supuesto nieto de Alonso del Castillo, Miguel de Luna, que le hacían hijo de Alonso de Luna, han sido puestas en entredicho por M. GARCíA-AREnAL y F. Rodríguez Mediano en «Médico, traductor, inventor: Miguel de Luna, cristiano arábigo en Granada», Chronica Nova, 32, 2006, pp. 187-231 y en Un oriente español: los moriscos y el Sacromonte en tiempos de Contrarreforma, Madrid, 2010. 
pacidad y el dominio de los idiomas se habían convertido en un potencial apreciado por las autoridades de la que el entorno familiar del romanceador habría sacado partido. Ya que estas familias debían encontrarse entre los grupos de moriscos que habrían evitado legalmente la expulsión, no en este caso por su estatus sino por privilegios obtenidos en función de sus servicios. Tal y como relataba la provisión real que anteriormente hemos referido.

Esto sin embargo no fue suficiente para evitarles los recelos que surgieron sobre sus personas al haber sido los primeros en enfrentarse a la tarea de la traducción de los textos sacromontanos. Ya comentamos en párrafos precedentes que su catolicismo se había puesto en duda, pero a esto hay que unir lo que llegaron a sentir como una amenaza contra sus bienes y personas, haciendo esta extensiva a sus familias. Así se expresa abiertamente Miguel de Luna en una carta que escribió en febrero de 1611 al arzobispo de Granada, al considerar como un peligro inminente el de la posibilidad de su expulsión ${ }^{18}$. La tan temida situación no llegó y de Luna acabó sus días en la ciudad de Granada donde se enterró cristianamente.

Pero el destino de sus descendientes debió ser bien distinto y estar marcado por la sombra de la sospecha que habían heredado. Así es como Alonso de Luna fue arrestado por la Inquisición en 1618 y acusado de difundir ideas heréticas ${ }^{19}$. Y es posible que la venta de la casa que había sido de Alonso del Castillo por otro de sus nietos en 1614 estuviese motivada por al agravamiento en una situación cada vez más opresiva. Y es aquí donde aparece la figura del sacerdote Luis de la Cueva como comprador de esta propiedad.

Puesto que la posibilidad del origen morisco de Luis de la Cueva es algo que desconocemos y que hasta el momento sólo ha apuntado el Dr. Mondéjar, no podemos deducir que estuviese en un entorno cercano a los descendientes del romanceador por meros contactos étnicos. Aún así pudo ser la ayuda necesaria en un momento de dificultad para los descendientes de Alonso del Castillo que aún vivían en la ciudad de Granada. Si nos planteamos que la venta de la casa pudiera haberse tomado como una medida de cierta urgencia, es normal pensar que se hubiera buscado a los posibles compradores entre un sector de la población que no sólo contase con el capital suficiente (no podemos establecer si el precio de venta es un indicativo de que ésta se realizara por debajo de su valor de mercado en aquel momento), sino que no temiese verse involucrado en especulaciones gratuitas por su contacto con moriscos o descendientes de moriscos sospechosos.

Como ya explicamos anteriormente, Luis de la Cueva como sacerdote quedaría fuera de ese círculo de dudosa afinidad que podía estar en el medio fa-

18. Esta es transcrita íntegramente en M. GARCíA-ARENAL, «El entorno de los plomos: historiografía y linaje», Los plomos del Sacromonte. Invención y Tesoro, pp. 76-77.

19. G.A. Wiegers, «Nueva luz sobre Alonso de Luna, alias Muhammad b. Abi 1-Asi, y su proceso inquisitorial (1818)», Los plomos del Sacromonte. Invención y Tesoro, pp. 403-417. 
miliar de Alonso del Castillo. Sin embargo, los últimos estudios presentados por García-Arenal referentes a los inspiradores de las falsificaciones plúmbeas han ampliado considerablemente el que hasta hace poco era un estrecho cerco de sospecha que parecía restringirse al binomio del Castillo y de Luna. Ya que esta investigadora ha señalado que posiblemente tras los polémicos hallazgos hubiera un proyecto ambicioso concebido por un grupo de moriscos y de cristianos viejos y ha identificado concretamente el entorno de los Núñez Muley y de los Granada Venegas como los principales impulsores del mismo ${ }^{20}$.

No tenemos datos suficientes para afirmar que Luis de la Cueva, del que apenas hay unos pocos apuntes biográficos, se encontrara en contacto con este reducto socialmente elevado de la población granadina de origen morisco. El que en su testamento actúe como testigo un tal Pedro de Zegrí, del que solo sabemos que era vecino de Granada, y que en el contrato de compraventa aparezca como fiador Jerónimo Venegas, de quien únicamente se apunta el dato de su participación como diligenciero, no nos permiten asegurar más que la identidad de dos personas cuyos apellidos delatan su origen morisco. Pero las fechas en las que se otorgaron ambos documentos, 1616 y 1614 respectivamente, delatan que estos debían pertenecer a ese favorecido grupo de familias que no abandonaron la península tras los sucesivos decretos de expulsión y por tanto los acercan a ese reducto selecto que apuntaba Mercedes García-Arenal en sus artículos.

Pero a todo esto hay un último dato que creemos importante tomar en consideración y es la abierta adscripción que realiza el presbítero Luis de la Cueva a los contenidos de los textos plúmbeos en su vertiente inmaculadista. Ya que a este respecto dispuso que se dijeran unas misas en honor a la Inmaculada Concepción de María bajo el lema que sería después de la abadía sacromontana y del enorme movimiento ideológico que se generó en Granada y en el que estos controvertidos hallazgos actuaron como un potente catalizador.

No podemos afirmar que la totalidad de los contenidos de estos libros fueran conocidos por de la Cueva, pero lo que sí deja claro es su ferviente adhesión a la principal causa religiosa que dirigió el promotor y fundador de la abadía del Sacromonte, Pedro de Castro. Recordemos que el impacto en la sociedad granadina fue inmenso, y muy especialmente entre el sector eclesiástico, ya que los hallazgos, independientemente de su originalidad o no, se convirtieron en el revulsivo ideológico del final de la Edad Moderna en una ciudad sobre la que se cernía la crisis como era la Granada de finales del XVI y principios del XVII. Y es justo en esas coordenadas donde debemos enmarcar la producción de Luis de la Cueva. Tanto su obsesión por la grandeza del pasado y la valoración de la antigüedad de los orígenes sin molestarse en distinguir los hechos históricos de los míticos, como en su defensa del aún no proclamado dogma de la Inmaculada a la luz de los recientes descubrimientos en la ciu-

20. M. GARCíA-ARENAL, op. cit., pp. 77-78. 
dad. Aun así, intencionadamente o no, y para no animar la duda sobre su memoria, sería su lápida concluida en su epitafio con la frase "la iglesia católica nunca yerra" la que se encargaría de fijar su futura y definitiva adscripción a la causa última que no sería otra que la salvación de su alma.

\section{RESUMEN}

En este artículo tratamos de exponer la conexión que se produce entre dos singulares personajes de la Granada moderna, el médico y traductor Alonso del Castillo y el sacerdote Luis de la Cueva. Esta se deriva indirectamente a través de la documentación generada por el expediente de la capellanía de misas fundada por de la Cueva y la aportación de un contrato de compra venta de una casa que pretende ser el soporte económico de dicha fundación piadosa.

Palabras clave: Granada, Edad Moderna, fundación piadosa, moriscos, traductor.

\section{ABSTRACT}

In this article we expose the connection between two unique characters of the modern Granada, physician and translator Alonso del Castillo and the priest Luis de la Cueva. This is derived indirectly through the documentation generated by the record of the pious foundation by de la Cueva and the provision of a contract of sale of a house that claims to be the financial support of the pious foundation.

Key words: Granada, Early modern Age, pious foundation, new Christians, translator. 